Review

\title{
Intraoperative Imaging-Guided Cancer Surgery: From Current Fluorescence Molecular Imaging Methods to Future Multi-Modality Imaging Technology
}

Chongwei Chi ${ }^{1}$, Yang Du ${ }^{1}$, Jinzuo Ye ${ }^{1}$, Deqiang Kou ${ }^{3}$, Jingdan Qiu ${ }^{3}$, Jiandong Wang ${ }^{3}$, Jie Tian ${ }^{\circledR}$ and Xiaoyuan Chen ${ }^{2}$

1. Key Laboratory of Molecular Imaging of Chinese Academy of Sciences, Institute of Automation, Chinese Academy of Sciences, Beijing, 100190, China.

2. Laboratory of Molecular Imaging and Nanomedicine, National Institute of Biomedical Imaging and Bioengineering (NIBIB), National Institute of Health (NIH), Bethesda, MD, 20892, USA.

3. Department of General Surgery, General Hospital of People's Liberation Army, Beijing 100853, China.

$\triangle$ Corresponding author: Dr. Xiaoyuan Chen, Email: shawn.chen@nih.gov Or Dr. Jie Tian, E-mail: tian@ieee.org; jie.tian@ia.ac.cn.

( ) Ivyspring International Publisher. This is an open-access article distributed under the terms of the Creative Commons License (http://creativecommons.org/ licenses/by-nc-nd/3.0/). Reproduction is permitted for personal, noncommercial use, provided that the article is in whole, unmodified, and properly cited.

Received: 2014.06.13; Accepted: 2014.07.31; Published: 2014.08.15

\begin{abstract}
Cancer is a major threat to human health. Diagnosis and treatment using precision medicine is expected to be an effective method for preventing the initiation and progression of cancer. Although anatomical and functional imaging techniques such as radiography, computed tomography (CT), magnetic resonance imaging (MRI) and positron emission tomography (PET) have played an important role for accurate preoperative diagnostics, for the most part these techniques cannot be applied intraoperatively. Optical molecular imaging is a promising technique that provides a high degree of sensitivity and specificity in tumor margin detection. Furthermore, existing clinical applications have proven that optical molecular imaging is a powerful intraoperative tool for guiding surgeons performing precision procedures, thus enabling radical resection and improved survival rates. However, detection depth limitation exists in optical molecular imaging methods and further breakthroughs from optical to multi-modality intraoperative imaging methods are needed to develop more extensive and comprehensive intraoperative applications. Here, we review the current intraoperative optical molecular imaging technologies, focusing on contrast agents and surgical navigation systems, and then discuss the future prospects of multi-modality imaging technology for intraoperative imaging-guided cancer surgery.
\end{abstract}

Key words: Optical molecular imaging; Intraoperative imaging-guided cancer surgery; Near-infrared fluorescence; Multi-modality Imaging; Indocyanine green.

\section{Introduction}

Presently, nearly 13 million new cancer cases and 7.6 million cancer deaths occur worldwide each year [1]. From 1971 to 2011, the National Cancer Institute (NCI) spent about $\$ 90$ billion on research, treatment, and prevention of cancer and is approaching a 5-year doubling of its budget [2-4]. The past decade has witnessed the rapid growth and technological advancement of imaging techniques; many of which have been applied for preoperative tumor diagnosis, most notably: radiography, computed tomography (CT), magnetic resonance imaging (MRI), positron emission tomography (PET), and single photon emission computed tomography (SPECT). However, these techniques are for the most part not applicable to intraoperative tumor surgery, for which palpation and visual inspection remain the predomi- 
nant methods [5].

Fluorescence molecular imaging (FMI) has been established as a powerful tool for guiding precise intraoperative positioning [6-9]. This technique can be described as a fluorescent labeling method that uses an imaging system to help surgeons distinguish between normal and malignant tissues labeled through the injection of a fluorescent detection agent. Over the past several years, this technology has improved the ability to surgically treat liver metastases [8], breast cancer [9-12], ovarian cancer [7], melanoma [13, 14], vulvar cancer $[15,16]$ and cervical cancer $[17,18]$.

Defining a way to objectively assess tumor margins during surgery plays a key role in diagnostic precision [19]. Traditionally, surgeons determine the tumor resection margin based on their experience and submit the specimen for histological evaluation. If the margin proves positive upon pathology, additional removal will be executed. Cytoreductive surgery followed by combination chemotherapy is also considered an effective treatment. The degree of cytoreduction predicts the tumor recurrence and survival, even if the residual tumor diameter is less than $1 \mathrm{~cm}$ after therapy [6, 7]. Remarkably, current studies suggest that FMI technology can assist surgeons in resecting micro-cancer tissues down to the submillimeter size, thus improving patient outcome [20-22].

With the aid of FMI technology, the prognosis of patients will as a result improve. For example, a study of breast cancer survivors at risk for breast cancer-related lymphedema found that early accurate treatment results in a better outcome and even complete resolution of lymphedema-associated complications [23]. Suzuki et al. used the FMI method with orally administered 5-aminolevulinic acid (5-ALA) to improve the prognosis of patients with glioma [24]; Loja et al. used Alexa-647 labeled pHLIP ( $\mathrm{pH}$ responsive peptide conjugated with Alexa Fluor (R) 647) to detect alterations in extracellular $\mathrm{pH}$ found in head and neck squamous cell carcinoma (HNSCC) in order to assess tumor margins during surgery, thus promoting better detection and prognosis of this cancer [25].

The most important components of FMI technology are the imaging contrast and surgical navigation system. Their further development will provide surgeons with intraoperative image guidance and information about residual tumors on follow-up. For clinical applications, the Food and Drug Administration (FDA) needs to approve fluorescence imaging contrast agents. The fluorescent dye indocyanine green (ICG) obtained approval and has been applied to sentinel lymph node (SLN) mapping $[10,12,17,26]$ and hepatic micrometastases detection [27].

However, ICG lacks precise targeting properties.
To enable more selective tumor detection, fluorescent dyes can be chemically conjugated with targeting moieties such as peptides, antibodies, or sugars, which are systemically metabolized and accumulate in lesion sites [28]. These fluorescent dyes, which are still in a preclinical stage, show potential as markers of cancer cells, tumor angiogenesis, and tumor microenvironments, but there are likely still a long way from FDA approval.

After injection of fluorescent dyes, a surgical navigation system is required to indirectly activate these dyes by supplying the tissues with near-infrared (NIR) light. Video rate images are provided by the system for accurate surgical guidance after fast image registration processing by a computer [29]. These techniques are therefore useful for providing surgeons with precise tumor detection in real-time during surgery.

FMI technology has proven to be a promising method for intraoperative tumor detection in clinical applications, although it is limited to the body's periphery. Therefore, other modalities have been introduced into image-guided surgery for more complete visualization of tumors. Kircher et al. reported a triple-modality MRI-photoacoustic-Raman method that helped to more accurately delineate the margins of brain tumors in living mice both preoperatively and intraoperatively [30]. This technique demonstrated the feasibility and advantages of multi-modal image-guided methods for precise characterization of the tumor margin during surgery.

To provide a better understanding of FMI technology, this review will focus on the innovative fields of instrumentation in clinical applications of FMI technology during cancer surgery. Owing to the current limitations of FMI technology, we will also describe methods for using multi-modalities and the potential long-term translational benefit for patients.

\section{Surgical Navigation Systems}

Intraoperative FMI technology relies on the availability of intraoperative imaging system and an imaging contrast agent to visualize the carcinoma in situ and metastatic lesions during surgery. Based on the tissue penetration depth, a high level of signal-to-background ratio (SBR) is required. The NIR range is between 700 and $900 \mathrm{~nm}$, at which light absorption and scattering are relatively low [31]. In recent years, the concept of using NIR fluorescence imaging has now been demonstrated experimentally, a crucial step towards its application in intraoperative image-guided surgery.

As NIR light cannot be seen directly with the naked eye, many academic and industrial groups have been devoted to the development of various 
imaging systems for intraoperative NIR FMI over the past few years [10, 29, 32-43]. Now, most of these systems have been applied to clinically and have made progress in assisting intraoperative tumor surgery. Besides attaining FDA approval, there are some important challenges for optimization of these systems for clinical use, including: real-time white light and fluorescence visualization, optimized NIR light-sources for sufficient fluorescence excitation, and convenience in clinical translation.

Several existing intraoperative FMI systems are available for clinical studies (Table 1). Existing systems can be classified into three categories as portable, functional and endoscopic and laparoscopic intraoperative FMI systems. Most of these systems have already been applied to clinical diagnosis and treatment. Furthermore, different types of systems have different performance focus. They have played an important role in operation convenience, improving image assessment and increasing detection depth. Now there are three systems have passed FDA approval. The Hamamatsu's (www.hamamatsu.com) Photodynamic Eye (PDE $\left.{ }^{\mathrm{TM}}\right)$, Artemis ${ }^{\mathrm{TM}}$ (www. o2view.com) and Novadaq SPYTM system (Novadaq Technologies Inc., Toronto, Canada) have already been applied in surgeries for breast cancer $[9,44]$, liver metastases [45] and bypassing graft surgery [46-51].

\section{Portable intraoperative FMI systems}

These surgical navigation systems are intended to assist in surgery and portable systems satisfy im- portant criteria for convenient operation. An effective system for intraoperative imaging needs to be able to readily facilitate the operation. $\mathrm{PDE}^{\mathrm{TM}}$ is a hand-held imaging system that emits annular NIR light and detects it through the in vivo uptake of fluorescent $2 \mathrm{D}$ images. The handheld capability and performance of the Fluoptics (www.fluoptics.com) Fluobeam ${ }^{\circledR}$ are similar to PDE, and it is now being used in clinical trials aiming to demonstrate the ability of FMI during and after an operation. PDE and Fluobeam possess the advantage of being compact and convenient for real-time fluorescence imaging. With the benefit of intraoperative visible images, Artemis ${ }^{\mathrm{TM}}$ simultaneously shows the color image and the fluorescent overlay, which provides excellent utility for nerve surgery $[52,53]$.

In the field of breast oncology, the SPY system has recently been applied to monitor skin perfusion in nipple-sparing mastectomies with ICG. This method can be seen as a useful adjunctive tool with potential to enable direct placement of mastectomy incisions and minimize ischemic complications [54]. Recently, some other interesting intraoperative imaging systems have been developed for clinical applications. For example, in the goggle system developed by the Department of Radiology at Washington University, the surgical navigation system is projected on wearable glasses, which frees the surgeon's hands so that an operation can be performed perform with more flexibility [43].

Table I. Parameter comparison of image-guided systems.

\begin{tabular}{|c|c|c|c|c|c|c|c|c|c|c|c|c|c|}
\hline $\begin{array}{l}\mathrm{N} \\
\mathrm{o}\end{array}$ & $\begin{array}{l}\text { Imaging } \\
\text { systems }\end{array}$ & Manufacturer & $\begin{array}{l}\text { Main } \\
\text { application }\end{array}$ & $\begin{array}{l}\text { Excita- } \\
\text { tion } \\
\text { wave- } \\
\text { length } \\
(\mathrm{nm})\end{array}$ & $\begin{array}{l}\text { Field of } \\
\text { view } \\
(\mathrm{mm})\end{array}$ & $\begin{array}{l}\text { Resolu- } \\
\text { tion }\end{array}$ & $\begin{array}{l}\text { Display } \\
\text { Refresh } \\
(\mathrm{Hz})\end{array}$ & $\begin{array}{l}\text { Dy- } \\
\text { nam- } \\
\text { ic } \\
\text { range } \\
\text { (bits) }\end{array}$ & $\begin{array}{l}\text { Working } \\
\text { distance } \\
(\mathrm{mm})\end{array}$ & $\begin{array}{l}\text { Color } \\
\text { video }\end{array}$ & $\begin{array}{l}\text { Light } \\
\text { source }\end{array}$ & $\begin{array}{l}\text { Clinical } \\
\text { Status }\end{array}$ & Reference \\
\hline 1 & SPY & $\begin{array}{l}\text { Novodaq Tech- } \\
\text { nologies, Mis- } \\
\text { sissauga, Cana- } \\
\text { da }\end{array}$ & $\begin{array}{l}\text { Intraoperative } \\
\text { Fluorescence } \\
\text { Imaging }\end{array}$ & 820 & $190 * 127$ & $\begin{array}{l}\text { Not spec- } \\
\text { ified }\end{array}$ & 30 & 8 & 300 & No & Laser & $\begin{array}{l}\text { FDA } \\
\text { approved }\end{array}$ & $\begin{array}{l}\text { www.novadaq } \\
\text {.com }\end{array}$ \\
\hline 2 & Artemis & $\begin{array}{l}\text { O2view, } \\
\text { Marken, The } \\
\text { Netherlands }\end{array}$ & $\begin{array}{l}\text { Stereoscopic } \\
\text { Fluorescence } \\
\text { Imaging }\end{array}$ & $400-1000$ & $\begin{array}{l}22.5^{*} 22.5 \\
\text { at } 50 \mathrm{~mm} \\
\text { distance }\end{array}$ & $659 * 494$ & $5-60$ & 14 & $\geq 50$ & Yes & Laser & $\begin{array}{l}\text { FDA } \\
\text { approved }\end{array}$ & $\begin{array}{l}\text { www.o2view. } \\
\text { com }\end{array}$ \\
\hline 3 & $\begin{array}{l}\text { Photody- } \\
\text { namic Eye }\end{array}$ & $\begin{array}{l}\text { Hamamatsu } \\
\text { Photonics, } \\
\text { Hamamatsu, } \\
\text { Japan }\end{array}$ & $\begin{array}{l}\text { Handheld } \\
\text { Fluorescence } \\
\text { Imaging }\end{array}$ & 760 & $100 * 67$ & $\begin{array}{l}\text { Not spec- } \\
\text { ified }\end{array}$ & $\begin{array}{l}\text { Not spec- } \\
\text { ified }\end{array}$ & 8 & 200 & No & LED & $\begin{array}{l}\text { FDA } \\
\text { approved }\end{array}$ & $\begin{array}{l}\text { www.hamama } \\
\text { tsu.com }\end{array}$ \\
\hline 4 & Fluobeam & $\begin{array}{l}\text { Fluoptics, } \\
\text { Grenoble, } \\
\text { France }\end{array}$ & $\begin{array}{l}\text { Handheld } \\
\text { Fluorescence } \\
\text { Imaging }\end{array}$ & $\begin{array}{l}690 \text { or } \\
780\end{array}$ & $128^{*} 94$ & $640 * 480$ & 30 & 12 & 150 & No & Laser & Clinical trial & $\begin{array}{l}\text { www.fluoptics } \\
\text {.com }\end{array}$ \\
\hline 5 & SurgOptix & $\begin{array}{l}\text { SurgOptix, } \\
\text { Redwood } \\
\text { Shores, USA }\end{array}$ & $\begin{array}{l}\text { Intraoperative } \\
\text { Fluorescence } \\
\text { Imaging }\end{array}$ & 520 & $115^{\star} 93$ & $1392 * 1024$ & 12 & 16 & 210 & Yes & Laser & Clinical trial & $\begin{array}{l}\text { www.surgopti } \\
\text { x.com }\end{array}$ \\
\hline 6 & FLARE & $\begin{array}{l}\text { Frangioni } \\
\text { Laboratory, } \\
\text { Boston, USA }\end{array}$ & $\begin{array}{l}\text { Intraoperative } \\
\text { Fluorescence } \\
\text { Imaging }\end{array}$ & $\begin{array}{l}670 \text { or } \\
760\end{array}$ & $150 * 113$ & $1280 * 1024$ & 15 & 12 & 450 & Yes & LED & Clinical trial & $\begin{array}{l}\text { www.centerfo } \\
\text { rmolecular- } \\
\text { imaging.org }\end{array}$ \\
\hline 7 & $\begin{array}{l}\text { GXMI } \\
\text { Navigator }\end{array}$ & $\begin{array}{l}\text { Institute of } \\
\text { Automtion, } \\
\text { Beijing, China }\end{array}$ & $\begin{array}{l}\text { Intraoperative } \\
\text { Fluorescence } \\
\text { Imaging }\end{array}$ & $760 \mathrm{~nm}$ & $250 * 250$ & $2456^{*} 2048$ & 17 & 16 & $>300$ & Yes & LED & Clinical trial & $\begin{array}{l}\text { www.3dmed. } \\
\text { net }\end{array}$ \\
\hline
\end{tabular}



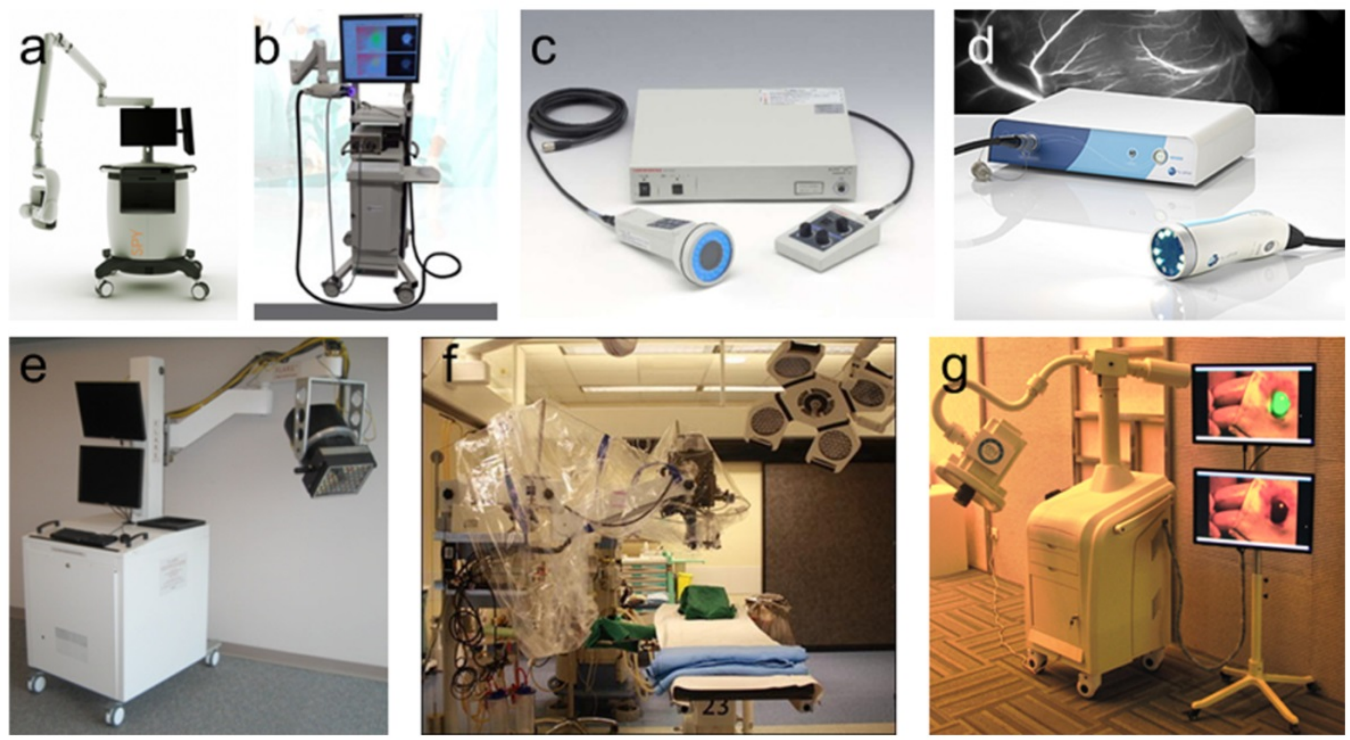

Figure I. Portable intraoperative FMl systems: a) The Novadaq SPYTM system, b) ArtemisTM, c) Hamamatsu's Photodynamic Eye (PDE TM), d) Fluoptics' Fluobeamß. Functional intraoperative FMI systems: e) FLARE ${ }^{T M}$ imaging system, f) Multispectral FMI system from Technische Universität München \& Helmholtz Zentrum, g) Surgical navigation system GXMI Navigator from the Institute of Automation, Chinese Academy of Sciences.

\section{Functional intraoperative FMI systems}

These functional systems have performance advantages in image capture and processing. The FLARE $^{\mathrm{TM}}$ imaging systems created in the Frangioni Laboratory (www.frangionilab.org) uses three cameras to simultaneously collect images from two different NIR channels and one visible channel. FLARE and mini FLARE systems are being tested in clinical trials, and have been applied to several forms of cancer surgery, most notably for intraoperative SLN mapping $[8,10,12,55,56]$. The multispectral FMI system from Technische Universität München \& Helmholtz Zentrum (http:/ / www.helmholtz-muenc hen.de) produced in collaboration with SurgOptix (SurgOptix Inc., Redwood Shores, CA, USA) has the advantage of being able to correct for the attenuation of the excitation of light and also can be applied to clinical cancer research [7, 15, 17, 57-59]. These two imaging systems perform well in multi-spectral imaging and improve image quality.

Another surgical navigation system is the GXMI Navigator developed in our Key Laboratory of Molecular Imaging at the Chinese Academy of Sciences (http://www.3dmed.net/). This device retains the advantage of convenient operation, while also improving the quality of imaging results [60]. Similar to the shadowless lamp, the system uses feature points to ensure rapid and precise imaging through the fusion of two cameras and has been applied in SLN mapping of patients in early stages of breast cancer. The systems are all are shown in figure 1.

\section{Endoscopic and laparoscopic FMI systems}

In recent years, endoscopic and laparoscopic systems have been coupled with FMI technology to solve the detection depth problem. These endoscopic and laparoscopic systems have been successfully applied in cancer surgery and have assisted in minimally invasive cancer therapy [61]. However, one cannot palpate tumors or handle the tumor-riddled organs via endoscopic or robotic surgery. It will be great help for surgeons to dissect tumors with guidance from high resolutions SBR images. Yokoyama et al. used the ICG fluorescence method to aid in endoscopic surgery for head and neck cancer. This technique produced fluorescent images with a significant contrast between tumor and normal tissues [62].

Wide application of FMI technology in endoscopic and laparoscopic surgery faces the challenging problem of how to adjust the endoscopic optical path to simultaneously achieve visible and NIR fluorescent images. When there is an established component between the endoscope and camera, it is difficult in many existing endoscopic applications to change the regular workflow and integrate the FMI technology.

Several studies have however demonstrated successful integration of fluorescence imaging capabilities into experimental endoscopic and laproscopic systems. Oh et al. presented a wide-field multi-channel fluorescence endoscopic system for early detection and treatment of colon cancer with matrix metalloproteinases (MMP) conjugated with quantum dots [63]. Matsui et al. used a custom NIR fluorescence laparoscopy system to identify the extrahepatic bile ducts in Yorkshire pigs. The results demonstrated 
good sensitivity for the identification of extrahepatic bile ducts and their functional status [64]. This laparoscopy system was also successfully applied for the fluorescence-guided identification of the ureters using methylene blue in pig experiments [65].

Based on these previous achievements, Venugopal et al. built a prism-based dual-channel endoscopic imaging system compatible with two light sources in color and one in the NIR range with a 2-CCD camera. This system demonstrated two key advantage: 1) the imaging camera was compact enough to be operated easily by one hand during surgery and 2) the optical channels allowed for accurate registration for real-time image processing [66]. Another laparoscopy system similar to the dual-channel endoscopic system has also been described. Glatz et al. presented a video-rate color and NIR fluorescence laparoscopy system for the identification of colorectal tumor margins [67]. Taken together these advances indicate that endoscopic and laparoscopic systems with FMI technology are rapidly approaching clinical translation and will be available for use in patients in the near future [68].

\section{Multi-modal intraoperative surgical navigation system}

Intraoperative surgical techniques require development of dedicated intraoperative image-guided systems. Important progress has been achieved over the past few years in both fields; however, multimodal imaging methods and systems are still needed for clinical translation of these technologies. Currently, several fluorescence-imaging systems are already commercially available. However, image-guided intraoperative systems supplying three-dimensional precision tumor detection are still unavailable $[7,12$, 60].

Detection depth is the main limitation of the FMI method for some clinical applications. However, if this problem were overcome, this method would allow for intraoperative tumor margin detection, which would be clinically meaningful to both surgeons and patients. Questions remain regarding how to solve the depth limitation challenge, which is essential in enhancing the value of FMI technique and multi-modal methods. Ale et al. examined the in vivo performance of a camera-based hybrid fluorescence molecular tomography (FMT) system for 360 degree imaging combined with X-ray computed tomography (XCT). This multi-modal method can provide concurrent anatomical and functional information. These findings indicate that FMI combined with the XCT method can increase the detection depth and may provide a substantial advance for current XCT applications [69].
Si et al. combined a single-cycle pulsed ultrasound modulation with digital optical phase conjugation. This multi-modal method has adequate optical power to focus light within high-scattering media for not only fluorescence imaging, but also numerous linear and nonlinear spectroscopy measurements. Xie et al. designed PET/NIR/MRI triple modality functional nanoparticles to achieve personalized tumor treatment. The results demonstrated that a tumor can be visualized in vivo in the U87MG xenograft mouse model by this triple modality [70]. As the diffuse gliomas are not always detected by contrast-enhancement MRI, Ewelt et al. introduced a method performed in 30 patients using ${ }^{18} \mathrm{~F}$-FET and Gadolinium-enhanced MRI for pre-operative diagnosis and 5-aminolevulinic derived tumor fluorescence for intraoperative image-guided malignant glioma dissection. The results showed $70.5 \%$ sensitivity and 92.3\% specificity using the multi-modal method, which supplied valuable pre-diagnostic imaging information and assisted in fluorescence-guided tumor resection [71].

In summary, the multi-modal imaging systems and technology can compensate the limit of detection depth in fluorescence imaging by imaging processing method and set the standard for many important applications in biological research and clinical trials [72].

\section{Clinical Applications}

\section{Clinical applications using ICG}

Although many NIR fluorescent molecules have been developed for tumor targeting, it will take time for their translation into clinical applications. The FDA approved molecule ICG can be used in ocular, cardiocirculatory, and liver function diagnostics. Recent reports focusing on intraoperative SLN mapping and HCC detection have further extended its clinical application.

Tumor metastasis usually occurs through the lymphatic system and the SLN is typically the first anatomical location of tumor metastasis. Currently, most researchers performing SLN mapping use a visible blue dye (such as isosulfan blue, patent blue, or methylene blue), a radioactive tracer (such as $99 \mathrm{mTc}$ or sulfur colloid), or a combination of the two. The blue dye is widely used for its low price and ease of use. However, the light emitted by the dye cannot pass through the skin and adipose tissue if the dose is not properly controlled. Further, some side effects such as tissue necrosis may result from the dye. In fact, the rate of successful tumor identification using a single dye is not satisfactory [73]. The surgeon may instead employ radioactive detection methods in which a radiation counter is used to detect and locate the SLN on 
the surface of the tissue with the radioactive element $99 \mathrm{~m}$ Tc. The two methods for intraoperative detection and localization are often combined to improve the detection rate of SLN [73, 74]. Although this combination method improves detection results, side effects and radioactive hazards still remain problematic.

FMI using ICG provides new opportunities to improve the SLN procedure [75]. The application of ICG shows a high SBR, which helps the surgeons locate the SLN before excision through real-time observation. As ICG is clinically available, many intraoperative imaging systems have focused on SLN cases. NIR fluorescence image-guided SLN mapping has been extensively used in oropharyngeal [56, 76], breast [10, 77-84], melanoma [13, 85-90], lung [91-98], esophageal [99], gastric [100-113], cervical [18, 114-117], colorectal [42, 55, 118-121], endometrial [122-124] and vulvar cancer cases [15, 16, 125]. The results have demonstrated the feasibility of intraoperative SLN mapping using FMI technology.

As blue dye can be visualized with the naked eye and has already been widely used in SLN mapping studies, the combined use of blue dye and ICG has been assessed. Sugie et al. found that a high rate of SLN detection was achieved using the ICG fluorescence method [9]. Since the optical penetration depth $(<10 \mathrm{~mm})$ limits the visualization of deep tissues, Verbeek et al. used blue dye, ICG and radionuclides in combination, which increased the detection accuracy rate (rising to $78 \%$ for blue dye, $100 \%$ for NIR fluorescence, and $88 \%$ for radioactivity) [126].

Although blue dyes, ICG, and radionuclides can effectively trace the location of SLNs, they also travel from the injection site to higher tier nodes. To prevent migration, dyes are modified to inhibit migration; radionuclides are commonly conjugated to a colloid to increase the hydrodynamic diameter or to a ligand to increase retention [127]. For fluorescent dyes, the choice of conjugant can affect the optical properties, as ICG cannot be conjugated covalently to sulfur colloids without altering its chemical structure [128]. The performance of targeting tracers should be further evaluated in direct comparison to existing agents for clinical use.

As the FDA approval of ICG has played an important role in clinical SLN mapping, some recent studies have reported on the detection of HCC using intraoperative FMI technology [45, 129]. The strongest fluorescent signals in patients were found if ICG was given several days before surgery as a routine preoperative liver function test [40, 129-133]. These reports offer new opportunities for intraoperative pancreatic tumor visualization.

With the advent of FMI techniques and systems, intraoperative liver cancer and metastases resection is becoming a simple, low-risk, and highly sensitive procedure. Ishizawa et al. used ICG at the dose of 0.5 $\mathrm{mg} / \mathrm{kg}$ for routine liver function testing within 2 weeks of surgery to achieve highly sensitive identification of HCC through the visualization of noncancerous liver parenchyma around the tumor. The results showed that intraoperative ICG fluorescence imaging was useful for detecting superficially located small HCCs and confirming that these lesions had been removed with sufficient surgical margins [134].

Although liver cancer detection using ICG has already been proven to be feasible for clinical use, the true mechanism by which ICG accumulates in cancer-affected organs remains uncertain. In another study, Ishizawa et al. proved that uptake of ICG in differentiated HCC cells is mediated by $\mathrm{Na}^{+}$/ taurocholate cotransporting polypeptide (NTCP) and organic aniontransporting polypeptide 8 (OATP8) in bile duct disorders, causing ICG to adhere to cancerous tissues. This enables highly sensitive detection of HCC via intraoperative ICG fluorescence imaging [135]. ICG-fluorescent imaging prior to resection recognized 21 out of 41 HCCs $(51 \%)$, while all of the 16 metastases could be extensively characterized. This dye has further been successfully applied for the real-time differentiation of minute and grossly non-identifiable liver cancers [133].

\section{Clinical applications using tumor-specific agents}

ICG has FDA approval for many clinical applications. However, its inability to precisely and selectively target certain tumors and tissues limits its usefulness for many applications of intraoperative tumor detection. In 2011, European researchers reported intraoperative ovarian cancer detection by a folate receptor-a targeting fluorescent agent [7]. This method highlighted its potential applications in patients with ovarian cancer for improved intraoperative staging and more radical cytoreductive surgery. However, larger international multicenter studies using standardized, uniformly calibrated FMI systems are needed to further confirm the diagnostic (accuracy, sensitivity, and specificity) and therapeutic value of the reported approach in a larger series of patients. Results from studies of intraoperative surgical navigation system applications are shown in figure 2 .

With regard to early stage tumor targeting agents, Sturm et al. presented a tumor-specific ASY*-FITC probe that was used in early stage esophageal adenocarcinoma detection during surgery. Although the detection was challenging because of the premalignant lesions' flat appearance, $75 \%$ sensitivity and $97 \%$ specificity was achieved in this first in vivo human study. The results showed that this 
targeted imaging agent was safe and could be useful for guiding tissue biopsy and for early detection of esophageal neoplasia and potentially other cancers of epithelial origin [136].

Precise and specific targeting of tumors by selective detection agents would also be of high clinical value. Report on urokinase plasminogen activator (uPA) labeled with NIR dye supports the potential of
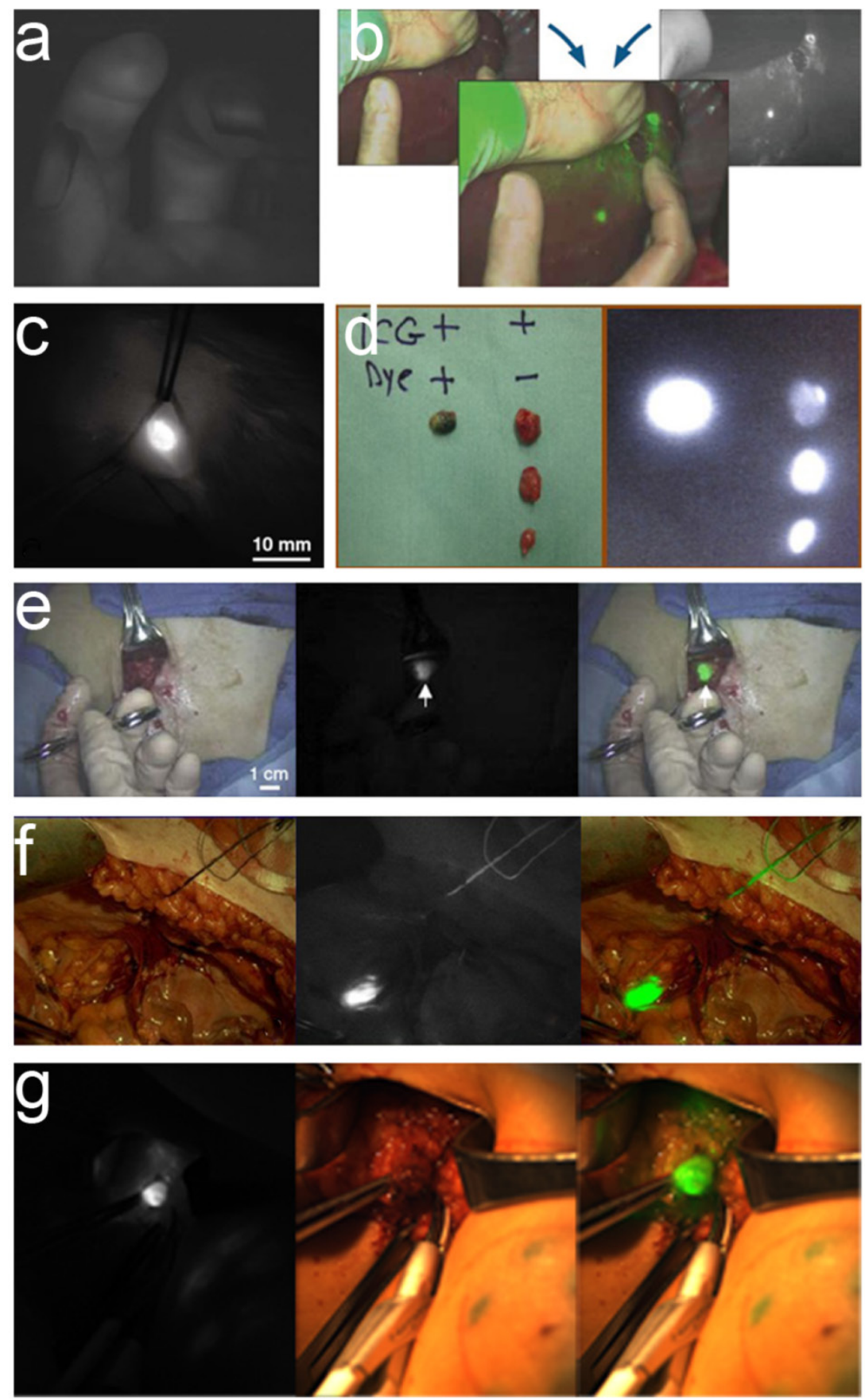

Figure 2. Clinical application results using surgical navigation systems. a) SPY imaging demonstrates perfusion to the thumb, index, and middle fingers via scanning with indocyanine green[142], b) Instructions for the Artemis Handheld system, c) Intraoperative NIR fluorescent image of the Fluobeam camera system[143], d) fluorescent signal and/or blue color of lymph nodes detected by PDE[I44], e) Single SLN identification by the FLARE system [10], f) In vivo fluorescence imaging of a lymph node detected by the Multispectral FMI system [17], g) ICG-guided intraoperative detection and resection of the SLN in humans by the surgical navigation system GXMI Navigator [60]. tumor margin imaging and theranostic for image-guided surgery [137]. A few targeted antibodies ally approved, such as bevacizumab against against HER2 [138]. A phase 1 clinical trial on breast cancer intraoperative visualization with bevacizumab conjugated to the IRDye $800 \mathrm{CW}$ has been approved and is undergoing trials [139]. In order to widely apply the intraoperative surgical navigation technology, clinical approved radionuclides using Cerenkov-induced fluorescence imaging can also be an effective method for intraoperative visualization of radiolabeled contrast agents [140]. Radiolabeled tumor-targeting peptides for molecular imaging, such as targeting integrin av $\beta 3$, have been successfully translated into the clinical setting and showed potential for NIR fluorescence imaging [141]. Currently, these advanced systems and agents are available to research-oriented clinical trials; hence, surgeons are verifying this method and extending their application.

\section{Preclinical Studies with Clinical Translational Poten- tial}

Recently, the non-targeted fluorescent dye ICG was adopted for clinical use after FDA approval. Current research focuses on increasing the availability of novel, fluorescently labeled agents to identify crucial landmarks, including: tumor margins, lymph nodes, and vital structures. Though many agents have proven their potential for clinical translation, profiles should first be considered before clinical use. Although many contrast agents have superior effectiveness in cancer detection, they may not be safe in patients and achieve FDA approval. Thus, satisfying safety profile requirements and the financial costs of clinical trials are challenges to the future approval of additional FMI agents.

Many promising imaging agents for different types of tumor targeting applications with clinical translational potential have been reported. Re- 
searchers have developed "smart" agents, which can for instance target tumor cells, tumor angiogenesis, or the tumor microenvironment. These "smart" agents specifically target either through conjugation with tumor-specific antibodies [145-147], nanobodies [148], aptamers, or peptides with high affinity binding for proteins on the cell surface [149]; or through the precise localization and amplification of enzymes for fluorescence activation [41, 150-154].

In order to provide molecularly specific detection of cancer cells, NIR fluorescent agents are usually conjugated with a specific targeting ligand or monoclonal antibody targeting tumor cell receptors, such as epidermal growth factor receptor (EGFR), human epidermal growth factor receptor-2 (HER2), or vascular endothelial growth factor (VEGF) receptor [155-157]. Heath et al. conjugated the fluorescenct dye (IRDye800CW) to a monoclonal antibody targeting EGFR to detect head and neck squamous cell carcinoma (HNSCC) in preclinical models. The specificity of tumor detection was confirmed by histology and immunohistochemistry ( $\mathrm{n}=25$ of 25 ). The results demonstrate the feasibility of detection and dissection of HNSCC using this probe in clinical settings [158].

Sano et al. synthesized two probes, AlexaFluor680 conjugated panitumumab to target EGFR and ICG conjugated trastuzumab to target against HER2, to evaluate the feasibility of specifically detecting breast cancer cells in vitro and in vivo. The results showed specific expression in two breast tumor cell lines, MDA-MB-468 (EGFR+/HER2-) and 3T3/HER2 (EGFR-/HER2+), by the two activatable fluorescent probes. By using this method, intraoperative breast cancer molecular subtype classification can be realized [159]. For example, Scheltinga et al. labeled Zr-89 in the anti-VEGF antibody bevacizumab and anti-HER2 antibody trastuzumab with IRDye $800 \mathrm{CW}$. Tumor uptake of the probes was determined in xenograft mice with radioactive counterparts for PET. Submillimeter level tumor lesions were also detected by real-time intraoperative FMI imaging method and confirmed by histology, immunohistochemistry, and fluorescence microscopy analyses [160]. The prospects of these cancer cell-specific imaging methods are encouraging for their future clinical translation to intraoperative image-guided surgery.

For the imaging of tumor angiogenesis, the molecule alpha-v-beta-3 ( $\operatorname{av} \beta 3)$ integrin is widely used [161] , as it targets neovascularization at the tumor sites and can be visualized by conjugating it to an NIR fluorescent dye such as Cy 5.5 or IRdye800CW. Cyclic arginine-glycine-aspartate (RGD) is the commonly used ligand for targeting av $\beta 3$. However, the existing drawback of RGD is its short blood circulation half-life, which greatly compromises its targeting efficacy. Chen et al. have solved this problem with a cyclic peptide. The $c($ RGDyK $)$ and an organic dye (IRDyc800 or Cy5.5) were covalently bound to human serum albumin (HSA), which improved the robustness of RGD targeting. Histology indicated that tumor vascular binding initially occurred where both tumor blood vessels and cell integrin were bound in vivo. This method may also be applied to other peptide-based probes that can be combined with HSA or other molecules for long-lasting tumor contrast and enhanced pharmacokinetics [162]. As further example, quantum dots (Qdots) possess excellent brightness, photostability, monodispersity, and fluorescent yield [163]. Li et al. synthesized cyclic RGD to the surface of NIR CdTe Qdots. Image-guided surgery was accomplished successfully with clear tumor margins visualization intraoperatively, demonstrating their potential for intraoperative tumor dissection [164].

The activatable strategy for the imaging tumor microenvironment takes advantage of the differences between tumor cells and normal cells, such as specific enzymes, $\mathrm{pH}$ value, temperature and other stimulations [165]. In vitro, these activatable probes are either not fluorescent or have little fluorescence due to the quenching effects of these conditions; however, after specific activation at the target site in vivo, they achieve strong fluorescence through the effect of dequenching. When the probes are activated, they exhibit high SBR compared to a constitutively fluorescent agent [19, 20, 166-173].

In order to improve SBR effectiveness, Elamprakash et al. designed a ratiometric activatable cell-penetrating peptide (RACPP) and coupled it with the fluorescence resonance energy transfer (FRET) technique using $\mathrm{Cy} 5$ and $\mathrm{Cy} 7$ dyes. Such ratiometric imaging increased SBR 40-fold and provided an accelerated and quantifiable metric to identify primary tumors and metastases in liver and lymph nodes with increased sensitivity and specificity [20].

For the purpose of real-time imaging, Zhu et al. discovered a method, which in a small animal model is able to boost fluorescent signals upon protease cleavage of the target molecule approximately half an hour post-injection. A strong fluorescent signal is then sustained for up to 24 hours. This particular method can identify any target protease with a specific peptide substrate and can adapt to a variety of real-time imaging applications, such as in vivo drug screening, drug efficacy trials, disease onset monitoring, and animal model development [166].

In order to improve sensitivity, Myochin et al. derived a new strategy to obtain a NIR fluorescence probe that can be rapidly activated by extracellular MMP. This design can be applied to develop a range 
of more sensitive and rapidly responsive NIR fluorescent probes not only for MMP activity, but also for other proteases [168]. However, the major limitation for the clinical application of new NIR fluorescent agents is that each fluorophore-ligand conjugate must receive regulatory approval separately, which is costly and time consuming [174].

Radionuclide probes are FDA approved and widely used clinically. These agents can be used to generate Cerenkov luminescence (CL), which is light generated when charged particles exceed the speed of light in a dielectric medium. Recently, the feasibility of CL imaging in patients undergoing diagnostic ${ }^{18}$ F-FDG scans to detect nodal disease has been validated in clinical experiments [140]. This means that optical methods for the detection of numerous radionuclide probes can be applied in clinical practice. In addition to enabling Cerenkov optical imaging for intraoperative clinical use, tumor-specific clinical applied radiotracers have synergistic advantages for PET-based diagnostics and therapeutics. Thorek et al. reported that disease markers were detected using nanoparticles to produce secondary Cerenkov-induced fluorescence and could be applied to monitor other markers, representing a shift toward activatable nuclear medical agents [175]. New approaches using clinical PET tracers to produce secondary Cerenkov-induced fluorescence provide us with the opportunity to adopt their use for surgical applications [175]. These FDA approved radioactive agents expand the range of applications available during surgery $[176,177]$.

\section{Conclusions and Perspectives}

Precise medical diagnosis and treatment will approved the ability of surgeons to treat cancer. Intraoperative image-guided cancer surgery using FMI technology may provide the most valuable goal for addressing diseased and abnormal tissues in surgical practice. White-light reflectance supplies insufficient visual information between the tumor and normal tissue, whereas fluorescence can provide additional information to potentially prevent cancer persistence or recurrence, and unacceptable morbidity. Although FMI technology has been of substantial benefit to patient outcomes, much more work is necessary for clinical translation of the rapidly expanding number of targeted agents and imaging systems currently in the research pipeline.

Intraoperative FMI has good performance in clinical applications, and many patients benefit from this method. As penetration depth is a challenge in optical imaging, intraoperative multimodal data fusion (such as adding rescanned CT and/or ultrasonography) provides possible solutions [45, 178, 179].
These techniques will augment the tools for accurate preoperative diagnosis, such as radiography, CT, MRI, and PET, which will provide important aid in advancing intraoperative FMI detection.

Some preclinical results using the NIR imaging technique combined with other imaging methods such as ultrasonography [45], MRI [180] and X-ray CT [178] compensate for the depth issues and have already demonstrated the possibility of using the FMI guided multi-modality method to precisely excise tumors. Zhang et al. declared that tumor metastatic lymph nodes and reactive lymph nodes located in deep-seated area were distinguished with diffusion-weighted and super-paramagnetic iron oxide enhanced MR imaging [181]. Visualization of tumor draining SLNs at distant depths using NIR, MR and PET triple-modal imaging methods was done in a 4T1 tumor metastasis model and provided helpful guidance for SLN mapping and tumor metastasis diagnosis thereby revealing its potential clinical utility [182]. With breakthroughs in computer-aided treatment technology, multi-modality image registration with optical imaging methods has achieved clinical use in intraoperative applications. Through the development of intraoperative image-guided agents and imaging systems in cancer surgery, FMI technology will extend other modality imaging methods into the clinic empowering surgeons to improve patient outcomes.

Finally, it is important for surgeons to incorporate intraoperative surgical navigation technology into their practice. Along with innovation in fluorescent agent development, there is a parallel path of innovation in the field of instrumentation that will extend the traditional view of surgery. Although these advances in FMI navigation have the potential to improve the surgical paradigm, there is the remaining challenge of defining clinical end points that will most benefit surgeons and patients utilizing these molecular navigation techniques. Minimally invasive surgical techniques have altered surgical practices in a way that coincides with and complements these promising technological advances. Minimally invasive surgical modalities have limited the handling of tissues, forcing surgeons to rely more heavily on tissue visualization. For open surgeries, real time improvement in visual differentiation between dissimilar tissue types during surgery will be particularly advantageous. With the development of imaging techniques and contrasts, FMI method can provide powerful assistance to theranostics for patients. Significant advances in intraoperative imaging-guided cancer surgery are expected in the next few years.

\section{Acknowledgments}

This paper is supported by the National Basic 
Research Program of China (973 Program) under Grant No. 2011CB707700, 2013CB733802, and 2014CB744503, the National Natural Science Foundation of China under Grant No. 81227901, 61231004, and 81371596, and the National Key Technology R\&D Program of China under Grant No.2012BAI23B01.

\section{Competing Interests}

The authors have declared that no competing interest exists.

\section{References}

1. Espina C, Porta M, Schuz J, Aguado IH, Percival RV, Dora C, et al. Environmental and occupational interventions for primary prevention of cancer: a cross-sectorial policy framework. Environ Health Perspect. 2013; 121: 420-6,

2. Marshall E. Cancer research and the $\$ 90$ billion metaphor. Science. 2011; 331: $1540-1$

3. [Internet] Varmus H. Professional Judgment Budget 2013. National Cancer Institute http:/ / www.cancer.gov/aboutnci/budget_planning_leg/plan-2013.

4. Kaiser J. The Advocate. Science. 2014; 343: 1460-1.

5. Vahrmeijer AL, Hutteman M, van der Vorst JR, van de Velde CJ, Frangioni JV. Image-guided cancer surgery using near-infrared fluorescence. Nat Rev Clin Oncol. 2013; 10: 507-18

6. Nguyen QT, Tsien RY. Fluorescence-guided surgery with live molecular navigation - a new cutting edge. Nat Rev Cancer. 2013; 13: 653-62.

7. van Dam GM, Themelis G, Crane LMA, Harlaar NJ, Pleijhuis RG, Kelder W, et al. Intraoperative tumor-specific fluorescence imaging in ovarian cancer by folate receptor-a targeting: first in-human results. Nat Med. 2011; 17: 1315-9.

8. van der Vorst JR, Schaafsma BE, Hutteman M, Verbeek FP, Liefers GJ, Hartgrink $\mathrm{HH}$, et al. Near-infrared fluorescence-guided resection of colorectal liver metastases. Cancer. 2013;119: 3411-8.

9. Sugie T, Sawada T, Tagaya N, Kinoshita T, Yamagami K, Suwa H, et al. Comparison of the indocyanine green fluorescence and blue dye methods in detection of sentinel lymph nodes in early-stage breast cancer. Ann Surg Oncol. 2013; 20: 2213-8.

10. Troyan SL, Kianzad V, Gibbs-Strauss SL, Gioux S, Matsui A, Oketokoun R, et al. The FLARE((TM)) Intraoperative Near-Infrared Fluorescence Imaging System: A First-in-Human Clinical Trial in Breast Cancer Sentinel Lymph Node Mapping. Ann Surg Oncol. 2009; 16: 2943-52.

11. Lee BT, Hutteman M, Gioux S, Stockdale A, Lin SJ, Ngo LH, et al. The FLARE intraoperative near-infrared fluorescence imaging system: a first-in-human clinical trial in perforator flap breast reconstruction. Plast Reconstr Surg. 2010; 126: $1472-81$

12. Mieog JSD, Troyan SL, Hutteman M, Donohoe KJ, Vorst JR, Stockdale A, et al. Toward Optimization of Imaging System and Lymphatic Tracer for Near-Infrared Fluorescent Sentinel Lymph Node Mapping in Breast Cancer. Ann Surg Oncol. 2011; 18: 2483-91.

13. Fujiwara M, Mizukami T, Suzuki A, Fukamizu H. Sentinel lymph node detection in skin cancer patients using real-time fluorescence navigation with indocyanine green: preliminary experience. J Plast Reconstr Aes. 2009; 62: E373-E8.

14. van der Vorst JR, Schaafsma BE, Verbeek FPR, Swijnenburg RJ, Hutteman M, Liefers GJ, et al. Dose optimization for near-infrared fluorescence sentinel lymph node mapping in patients with melanoma. Brit J Dermatol. 2013; 168: 93-8.

15. Crane LMA, Themelis G, Arts HJG, Buddingh KT, Brouwers AH, Ntziachristos $\mathrm{V}$, et al. Intraoperative near-infrared fluorescence imaging for sentinel lymph node detection in vulvar cancer: First clinical results. Gynecol Oncol. 2011; 120: 291-5.

16. Hutteman M, van der Vorst JR, Gaarenstroom KN, Peters AAW, Mieog JSD, Schaafsma BE, et al. Optimization of near-infrared fluorescent sentinel lymph node mapping for vulvar cancer. Am J Obstet Gynecol. 2012; 206: 89 e1-5.

17. Crane LM, Themelis G, Pleijhuis RG, Harlaar NJ, Sarantopoulos A, Arts HJ, et al. Intraoperative multispectral fluorescence imaging for the detection of the sentinel lymph node in cervical cancer: a novel concept. Mol Imaging Biol. 2011; 13: 1043-9.

18. van der Vorst JR, Hutteman M, Gaarenstroom KN, Peters AAW, Mieog JSD, Schaafsma BE, et al. Optimization of Near-Infrared Fluorescent Sentinel Lymph Node Mapping in Cervical Cancer Patients. Int J Gynecol Cancer. 2011; 21: $1472-8$

19. Nguyen QT, Olson ES, Aguilera TA, Jiang T, Scadeng M, Ellies LG, et al. Surgery with molecular fluorescence imaging using activatable cell-penetrating peptides decreases residual cancer and improves survival. Proc Natl Acad Sci USA. 2010; 107: 4317-22.

20. Savariar EN, Felsen CN, Nashi N, Jiang T, Ellies LG, Steinbach $P$, et al. Real-time in vivo molecular detection of primary tumors and metastases with ratiometric activatable cell-penetrating peptides. Cancer Res. 2013; 73: 855-64.
21. Nagtegaal ID, Quirke $P$. What is the role for the circumferential margin in the modern treatment of rectal cancer? J Clin Oncol. 2008; 26: 303-12.

22. Newman MI, Samson MC. The application of laser-assisted indocyanine green fluorescent dye angiography in microsurgical breast reconstruction. J Reconstr Microsurg. 2009; 25: 21-6.

23. Cooper G. Early diagnosis of lymphoedema helps to reduce its psychological and social impact. Nurs Times. 2010; 106: 15-7.

24. Suzuki T, Wada S, Eguchi H, Adachi J, Mishima K, Matsutani M, et al. Cadherin 13 overexpression as an important factor related to the absence of tumor fluorescence in 5-aminolevulinic acid-guided resection of glioma Laboratory investigation. J Neurosurg. 2013; 119: 1331-9.

25. Loja MN, Luo Z, Greg Farwell D, Luu QC, Donald PJ, Amott D, et al. Optical molecular imaging detects changes in extracellular $\mathrm{pH}$ with the development of head and neck cancer. Int J Cancer. 2013; 132: 1613-23.

26. Kitai T, Inomoto T, Miwa M, Shikayama T. Fluorescence navigation with indocyanine green for detecting sentinel lymph nodes in breast cancer. Breast Cancer. 2005; 12: 211-5.

27. Yokoyama N, Otani $\mathrm{T}$, Hashidate $\mathrm{H}$, Maeda $\mathrm{C}$, Katada $\mathrm{T}$, Sudo $\mathrm{N}$, et al. Real-time detection of hepatic micrometastases from pancreatic cancer by intraoperative fluorescence imaging: preliminary results of a prospective study. Cancer. 2012; 118: 2813-9.

28. Sevick-Muraca EM. Translation of Near-Infrared Fluorescence Imaging Technologies: Emerging Clinical Applications. Annu Rev Med. 2012; 63: 217-31.

29. Themelis G, Yoo JS, Soh K-S, Schulz R, Ntziachristos V. Real-time intraoperative fluorescence imaging system using light-absorption correction. J Biomed Opt. 2009; 14: 064012.

30. Kircher MF, de la Zerda A, Jokerst JV, Zavaleta CL, Kempen PJ, Mittra E, et al. A brain tumor molecular imaging strategy using a new triple-modality MRI-photoacoustic-Raman nanoparticle. Nat Med. 2012; 18: 829-34.

31. Chance B. Near-infrared images using continuous, phase-modulated, and pulsed light with quantitation of blood and blood oxygenation. Ann N Y Acad Sci. 1998; 838: 29-45.

32. Phillips BT, Lanier ST, Conkling N, Wang ED, Dagum AB, Ganz JC, et al. Intraoperative perfusion techniques can accurately predict mastectomy skin flap necrosis in breast reconstruction: results of a prospective trial. Plast Reconstr Surg. 2012; 129: 778e-88e.

33. Hirche $\mathrm{C}$, Engel H, Kolios L, Cognie J, Hünerbein M, Lehnhardt M, et al. An Experimental Study to Evaluate the Fluobeam 800 Imaging System for Fluorescence-Guided Lymphatic Imaging and Sentinel Node Biopsy. Surg Innov. 2013; 20: 516-23.

34. Nagafuji H, Nakamura T. Feasibility of ICG fluorescence-guided sentinel node biopsy in animal models using the HyperEye Medical System. Ann Surg Oncol. 2011; 18: 2042-7.

35. van der Poel HG, Buckle T, Brouwer OR, Valdés Olmos RA, van Leeuwen FW. Intraoperative laparoscopic fluorescence guidance to the sentinel lymph node in prostate cancer patients: clinical proof of concept of an integrated functional imaging approach using a multimodal tracer. Eur Urol. 2011; 60: 826-33.

36. Yamashita S-i, Tokuishi K, Anami K, Miyawaki M, Moroga T, Kamei M, et al. Video-assisted thoracoscopic indocyanine green fluorescence imaging system shows sentinel lymph nodes in non-small-cell lung cancer. J Thorac Cardiovasc Surg. 2011; 141: 141-4

37. Spinoglio G, Priora F, Bianchi PP, Lucido FS, Licciardello A, Maglione V, et al. Real-time near-infrared (NIR) fluorescent cholangiography in single-site robotic cholecystectomy (SSRC): a single-institutional prospective study. Surg Endosc. 2013; 27: 2156-62.

38. Borofsky MS, Gill IS, Hemal AK, Marien TP, Jayaratna I, Krane LS, et al. Near-infrared fluorescence imaging to facilitate super-selective arterial clamping during zero-ischaemia robotic partial nephrectomy. BJU Int. 2013; 111: 604-10.

39. Moroga T, Yamashita S-i, Tokuishi K, Miyawaki M, Anami K, Yamamoto S, et al. Thoracoscopic segmentectomy with intraoperative evaluation of sentinel nodes for stage I non-small cell lung cancer. Ann Thorac Cardiovasc Surg. 2011; 18: 89-94.

40. Gotoh K, Yamada T, Ishikawa O, Takahashi H, Eguchi H, Yano M, et al. HOW I DO IT A Novel Image-Guided Surgery of Hepatocellular Carcinoma by Indocyanine Green Fluorescence Imaging Navigation. J Surg Oncol. 2009; 100: 75-9.

41. Mieog JSD, Hutteman M, van der Vorst JR, Kuppen PJK, Que I, Dijkstra J, et al. Image-guided tumor resection using real-time near-infrared fluorescence in a syngeneic rat model of primary breast cancer. Breast Cancer Res Treat. 2011; 128: 679-89.

42. Cahill RA, Anderson M, Wang LM, Lindsey I, Cunningham C, Mortensen NJ. Near-infrared (NIR) laparoscopy for intraoperative lymphatic road-mapping and sentinel node identification during definitive surgical resection of early-stage colorectal neoplasia. Surg Endosc. 2012; 26: 197-204.

43. Liu Y, Njuguna R, Matthews T, Akers WJ, Sudlow GP, Mondal S, et al. Near-infrared fluorescence goggle system with complementary metal-oxide-semiconductor imaging sensor and see-through display. J Biomed Opt. 2013; 18: 101303.

44. Mohebali J, Gottlieb LJ, Agarwal JP. Further validation for use of the retrograde limb of the internal mammary vein in deep inferior epigastric perforator flap breast reconstruction using laser-assisted indocyanine green angiography. J Reconstr Microsurg. 2010; 26: 131-5. 
45. Peloso A, Franchi E, Canepa MC, Barbieri L, Briani L, Ferrario J, et al. Combined use of intraoperative ultrasound and indocyanine green fluorescence imaging to detect liver metastases from colorectal cancer. HPB (Oxford). 2013; 15: 928-34.

46. Yamamoto M, Sasaguri S, Sato T. Assessing intraoperative blood flow in cardiovascular surgery. Surg today. 2011; 41: 1467-74.

47. Day KE, Beck LN, Deep NL, Kovar J, Zinn KR, Rosenthal EL. Fluorescently labeled therapeutic antibodies for detection of microscopic melanoma. Laryngoscope. 2013; 123: 2681-9.

48. Desai ND, Miwa S, Kodama D, Koyama T, Cohen G, Pelletier MP, et al. A randomized comparison of intraoperative indocyanine green angiography and transit-time flow measurement to detect technical errors in coronary bypass grafts. J Thorac Cardiovasc Surg. 2006; 132: 585-94.

49. Perry D, Bharara M, Armstrong DG, Mills J. Intraoperative fluorescence vascular angiography: during tibial bypass. J Diabetes Sci Technol. 2012; 6: 204-8.

50. Sherwinter DA. Identification of anomolous biliary anatomy using near-infrared cholangiography. J Gastrointest Surg. 2012; 16: 1814-5.

51. Sherwinter DA, Gallagher J, Donkar T. Intra-operative transanal near infrared imaging of colorectal anastomotic perfusion: a feasibility study. Colorectal Dis. 2013; 15: 91-6

52. Gray D, Kim E, Cotero V, Staudinger V, Yazdanfar S, Tan Hehir C. A compact fluorescence and white light imaging system for intraoperative visualization of nerves. Proc SPIE. 2012;: 8207.

53. Keereweer S, Mol IM, Vahrmeijer AL, Van Driel PB, de Jong B, Robert J, et al. Dual wavelength tumor targeting for detection of hypopharyngeal cancer using near-infrared optical imaging in an animal model. Int J Cancer. 2012; 131: 1633-40.

54. Wapnir I, Dua M, Kieryn A, Paro J, Morrison D, Kahn D, et al. Intraoperative Imaging of Nipple Perfusion Patterns and Ischemic Complications in Nipple-Sparing Mastectomies. Ann Surg Oncol. 2014; 21: 100-6.

55. Hutteman M, Choi HS, Mieog JS, van der Vorst JR, Ashitate Y, Kuppen PJ, et al. Clinical translation of ex vivo sentinel lymph node mapping for colorectal cancer using invisible near-infrared fluorescence light. Ann Surg Oncol. 2011; 18: 1006-14.

56. van der Vorst JR, Schaafsma BE, Verbeek FPR, Keereweer S, Jansen JC, van der Velden LA, et al. Near-infrared fluorescence sentinel lymph node mapping of the oral cavity in head and neck cancer patients. Oral Oncol. 2013; 49: 15-9.

57. Crane LMA, Themelis G, Pleijhuis RG, Harlaar NJ, Sarantopoulos A, Arts $\mathrm{HJG}$, et al. Intraoperative Multispectral Fluorescence Imaging for the Detection of the Sentinel Lymph Node in Cervical Cancer: A Novel Concept. Mol Imaging Biol. 2011; 13: 1043-9.

58. Kijanka M, Warnders FJ, El Khattabi M, Lub-de Hooge M, van Dam GM, Ntziachristos V, et al. Rapid optical imaging of human breast tumour xenografts using anti-HER2 VHHs site-directly conjugated to IRDye $800 \mathrm{CW}$ for image-guided surgery. Eur J Nucl Med Mol Imaging. 2013; 40: 1718-29.

59. Pleijhuis RG, Langhout GC, Helfrich W, Themelis G, Sarantopoulos A, Crane LMA, et al. Near-infrared fluorescence (NIRF) imaging in breast-conserving surgery: Assessing intraoperative techniques in tissue-simulating breast phantoms. Eur J Surg Oncol. 2011; 37: 32-9.

60. Chi C, Ye J, Ding H, He D, Huang W, Zhang GJ, et al. Use of indocyanine green for detecting the sentinel lymph node in breast cancer patients: from preclinical evaluation to clinical validation. PloS One. 2013; 8: e83927.

61. Jafari MD, Lee KH, Halabi WJ, Mills SD, Carmichael JC, Stamos MJ, et al. The use of indocyanine green fluorescence to assess anastomotic perfusion during robotic assisted laparoscopic rectal surgery. Surg Endosc. 2013; 27: 3003-8.

62. Yokoyama J, Fujimaki M, Ohba S, Anzai T, Yoshii R, Ito S, et al. A feasibility study of NIR fluorescent image-guided surgery in head and neck cancer based on the assessment of optimum surgical time as revealed through dynamic imaging. Onco Targets Ther. 2013; 6: 325-30.

63. Oh G, Yoo SW, Jung Y, Ryu YM, Park Y, Kim SY, et al. Intravital imaging of mouse colonic adenoma using MMP-based molecular probes with multi-channel fluorescence endoscopy. Biomed Opt Express. 2014; 5: 1677-89.

64. Matsui A, Tanaka E, Choi HS, Winer JH, Kianzad V, Gioux S, et al. Real-time intra-operative near-infrared fluorescence identification of the extrahepatic bile ducts using clinically available contrast agents. Surgery. 2010; 148: 87-95.

65. Matsui A, Tanaka E, Choi HS, Kianzad V, Gioux S, Lomnes SJ, et al. Real-time, near-infrared, fluorescence-guided identification of the ureters using methylene blue. Surgery. 2010; 148: 78-86.

66. Venugopal V, Park M, Ashitate Y, Neacsu F, Kettenring F, Frangioni JV, et al. Design and characterization of an optimized simultaneous color and near-infrared fluorescence rigid endoscopic imaging system. Biomed Opt Express. 2013; 18: 126018

67. Glatz J, Varga J, Garcia-Allende PB, Koch M, Greten FR, Ntziachristos V. Concurrent video-rate color and near-infrared fluorescence laparoscopy. J Biomed Opt. 2013; 18: 101302.

68. Ali T, Choyke PL, Kobayashi H. Endoscopic molecular imaging of cancer. Future Oncol. 2013; 9: 1501-13.

69. Ale A, Ermolayev V, Herzog E, Cohrs $C$, de Angelis $M H$, Ntziachristos V. FMT-XCT: in vivo animal studies with hybrid fluorescence molecular tomography-X-ray computed tomography. Nat methods. 2012; 9: 615-20.

70. Xie J, Chen K, Huang J, Lee S, Wang JH, Gao J, et al. PET/NIRF/MRI triple functional iron oxide nanoparticles. Biomaterials. 2010; 31: 3016-22.

71. Ewelt C, Floeth FW, Felsberg J, Steiger HJ, Sabel M, Langen KJ, et al. Finding the anaplastic focus in diffuse gliomas: The value of Gd-DTPA enhanced MRI,
FET-PET, and intraoperative, ALA-derived tissue fluorescence. Clin Neurol Neurosur. 2011; 113: 541-7.

72. Si K, Fiolka R, Cui M. Fluorescence imaging beyond the ballistic regime by ultrasound-pulse-guided digital phase conjugation. Nat Photonics. 2012; 6: 657-61.

73. Motomura K, Inaji H, Komoike Y, Hasegawa Y, Kasugai T, Noguchi S, et al. Combination technique is superior to dye alone in identification of the sentinel node in breast cancer patients. J Surg Oncol. 2001; 76: 95-9.

74. Radovanovic Z, Golubovic A, Plzak A, Stojijkovic B, Radovanovic D. Blue dye versus combined blue dye-radioactive tracer technique in detection of sentinel lymph node in breast cancer. Eur J Surg Oncol. 2004; 30: 913-7.

75. van de Ven S, Wiethoff A, Nielsen T, Brendel B, van der Voort M, Nachabe R, et al. A Novel Fluorescent Imaging Agent for Diffuse Optical Tomography of the Breast: First Clinical Experience in Patients. Mol Imaging Biol 2010; 12: 343-8.

76. Bredell MG. Sentinel lymph node mapping by indocyanin green fluorescence imaging in oropharyngeal cancer - preliminary experience. Head Neck Oncol. 2010; 2: 31.

77. Murawa D, Hirche C, Dresel S, Hunerbein M. Sentinel lymph node biopsy in breast cancer guided by indocyanine green fluorescence. Br J Surg. 2009; 96: 1289-94.

78. Chiu CC. Sentinel lymph node biopsy in breast cancer guided by indocyanine green fluorescence (Br J Surg 2009; 96: 1289-1294). Br J Surg. 2010; 97: 455.

79. Sugie T, Kassim KA, Takeuchi M, Hashimoto T, Yamagami K, Masai Y, et al. A Novel Method for Sentinel Lymph Node Biopsy by Indocyanine Green Fluorescence Technique in Breast Cancer. Cancers (Basel). 2010; 2: 713-20.

80. Hirche C, Murawa D, Mohr Z, Kneif S, Hunerbein M. ICG fluorescence-guided sentinel node biopsy for axillary nodal staging in breast cancer. Breast Cancer Res Treat. 2010; 121: 373-8.

81. Noura S, Ohue M, Seki Y, Tanaka K, Motoori M, Kishi K, et al. Feasibility of a Lateral Region Sentinel Node Biopsy of Lower Rectal Cancer Guided by Indocyanine Green Using a Near-Infrared Camera System. Ann Surg Oncol. 2010; 17: 144-51

82. Hutteman M, Mieog JSD, van der Vorst JR, Liefers GJ, Putter H, Lowik CWGM, et al. Randomized, double-blind comparison of indocyanine green with or without albumin premixing for near-infrared fluorescence imaging of sentinel lymph nodes in breast cancer patients. Breast Cancer Res Treat. 2011; 127: $163-70$.

83. Polom K, Murawa D, Nowaczyk P, Rho YS, Murawa P. Breast cancer sentinel lymph node mapping using near infrared guided indocyanine green and indocyanine green--human serum albumin in comparison with gamma emitting radioactive colloid tracer. Eur J Surg Oncol. 2012; 38: 137-42.

84. Schaafsma BE, Verbeek FP, Rietbergen DD, van der Hiel B, van der Vorst JR, Liefers GJ, et al. Clinical trial of combined radio- and fluorescence-guided sentinel lymph node biopsy in breast cancer. Br J Surg. 2013; 100: 1037-44.

85. Namikawa K, Yamazaki N. Sentinel lymph node biopsy guided by indocyanine green fluorescence for cutaneous melanoma. Eur J Dermatol. 2011: 21: 184-90

86. Polom K, Murawa D, Rho YS, Spychala A, Murawa P. Skin melanoma sentinel lymph node biopsy using real-time fluorescence navigation with indocyanine green and indocyanine green with human serum albumin. Br J Dermatol. 2012; 166: 682-3

87. Gilmore DM, Khullar OV, Gioux S, Stockdale A, Frangioni JV, Colson YL, et al. Effective low-dose escalation of indocyanine green for near-infrared fluorescent sentinel lymph node mapping in melanoma. Ann Surg Oncol. 2013; 20: 2357-63.

88. Namikawa K, Tsutsumida A, Tanaka R, Kato J, Yamazaki N. Limitation of indocyanine green fluorescence in identifying sentinel lymph node prior to skin incision in cutaneous melanoma. Int J Clin Oncol. 2014; 19: 198-203.

89. van der Vorst J, Schaafsma B, Verbeek F, Swijnenburg R, Hutteman M, Liefers $\mathrm{G}$, et al. Dose optimization for near-infrared fluorescence sentinel lymph node mapping in patients with melanoma. Brit J Dermatol. 2013; 168: 93-8.

90. Uhara H, Yamazaki N, Takata M, Inoue Y, Sakakibara A, Nakamura Y, et al. Applicability of radiocolloids, blue dyes and fluorescent indocyanine green to sentinel node biopsy in melanoma. J Dermatol. 2012; 39: 336-8.

91. Kermani AT, Bagheri R, Tehranian S, Shojaee P, Sadeghi R, Krag DN. Accuracy of sentinel node biopsy in the staging of non-small cell lung carcinomas: Systematic review and meta-analysis of the literature. Lung Cancer. 2013; 80: 5-14.

92. Imai K, Minamiya Y, Saito H, Nakagawa T, Ito M, Ono T, et al. Detection of pleural lymph flow using indocyanine green fluorescence imaging in non-small cell lung cancer surgery: a preliminary study. Surg Today. 2013; 43: 249-54.

93. Gilmore DM, Khullar OV, Jaklitsch MT, Chirieac LR, Frangioni JV, Colson YL. Identification of metastatic nodal disease in a phase 1 dose-escalation trial of intraoperative sentinel lymph node mapping in non-small cell lung cancer using near-infrared imaging. J Thorac Cardiov Sur. 2013; 146: 562-9.

94. Yamashita S, Tokuishi K, Miyawaki M, Anami K, Moroga T, Takeno S, et al. Sentinel node navigation surgery by thoracoscopic fluorescence imaging system and molecular examination in non-small cell lung cancer. Ann Surg Oncol. 2012; 19: 728-33

95. Moroga T, Yamashita S, Tokuishi K, Miyawaki M, Anami K, Yamamoto S, et al. Thoracoscopic Segmentectomy with Intraoperative Evaluation of Sentinel Nodes for Stage I Non-Small Celll Lung Cancer. Ann Thorac Cardiovas. 2012; 18: 89-94. 
96. Yamashita S, Tokuishi K, Anami K, Miyawaki M, Moroga T, Kamei M, et al. Video-assisted thoracoscopic indocyanine green fluorescence imaging system shows sentinel lymph nodes in non-small-cell lung cancer. J Thorac Cardiov Sur. 2011; 141: 141-4.

97. Ito N, Fukuta M, Tokushima T, Nakai K, Ohgi S. Sentinel node navigation surgery using indocyanine green in patients with lung cancer. Surg Today. 2004; 34: 581-5.

98. Sugi K, Fukuda M, Nakamura H, Kaneda Y. Comparison of three tracers for detecting sentinel lymph nodes in patients with clinical N0 lung cancer. Lung Cancer. 2003; 39: 37-40.

99. Kubota K, Yoshida M, Kuroda J, Okada A, Ohta K, Kitajima M. Application of the HyperEye Medical System for esophageal cancer surgery: a preliminary report. Surg Today. 2013; 43: 215-20.

100. Takeuchi H, Kitagawa Y. New Sentinel Node Mapping Technologies for Early Gastric Cancer. Ann Surg Oncol. 2013; 20: 522-32.

101. Can MF, Yagci G, Cetiner S. Systematic Review of Studies Investigating Sentinel Node Navigation Surgery and Lymphatic Mapping for Gastric Cancer. J Laparoendosc Adv Surg Tech A. 2013; 23: 651-62.

102. Lee JH, Park DJ, Kim YH, Shin CM, Lee HS, Kim HH. Clinical Implementations of Preoperative Computed Tomography Lymphography in Gastric Cancer: A Comparison with Dual Tracer Methods in Sentinel Node Navigation Surgery. Ann Surg Oncol. 2013; 20: 2296-303.

103. Takeuchi H, Kitagawa Y. Sentinel Node Navigation Surgery in Patients with Early Gastric Cancer. Digest Surg. 2013; 30: 104-11.

104. Bok GH, Kim YJ, Jin SY, Chun CG, Lee TH, Kim HG, et al. Endoscopic submucosal dissection with sentinel node navigation surgery for early gastric cancer. Endoscopy. 2012; 44: 953-6.

105. Fujita T, Seshimo A, Kameoka S. Detection of Sentinel Nodes in Gastric Cancer by Indocyanine Green Fluorescence Imaging. Hepatogastroenterology. 2012; 59: 2213-6.

106. Wang Z, Dong ZY, Chen JQ, Liu JL. Diagnostic Value of Sentinel Lymph Node Biopsy in Gastric Cancer: A Meta-Analysis. Ann Surg Oncol. 2012; 19: 1541-50.

107. Polom K, Murawa D, Rho YS, Nowaczyk P, Hunerbein M, Murawa P. Current Trends and Emerging Future of Indocyanine Green Usage in Surgery and Oncology A Literature Review. Cancer. 2011; 117: 4812-22.

108. Kelder W, Nimura H, Takahashi N, Mitsumori N, van Dam GM, Yanaga K. Sentinel node mapping with indocyanine green (ICG) and infrared ray detection in early gastric cancer: An accurate method that enables a limited lymphadenectomy. Eur J Surg Oncol. 2010; 36: 552-8.

109. Tajima Y, Yamazaki K, Masuda Y, Kato M, Yasuda D, Aoki T, et al. Sentinel Node Mapping Guided by Indocyanine Green Fluorescence Imaging in Gastric Cancer. Ann Surg. 2009; 249: 58-62.

110. Kusano M, Tajima Y, Yamazaki K, Kato M, Watanabe M, Miwa M. Sentinel node mapping guided by indocyanine green fluorescence imaging: A new method for sentinel node navigation surgery in gastrointestinal cancer. Digest Surg. 2008; 25: 103-8.

111. Ohdaira H, Nimura H, Mitsumori N, Takahashi N, Kashiwagi H, Yanaga K. Validity of modified gastrectomy combined with sentinel node navigation surgery for early gastric cancer. Gastric Cancer. 2007; 10: 117-22

112. Morita D, Tsuda H, Ichikura T, Kimura M, Aida S, Kosuda S, et al. Analysis of sentinel node involvement in gastric cancer. Clin Gastroenterol Hepatol. 2007; 5: 1046-52.

113. Ishikawa K, Yasuda K, Shiromizu A, Etoh T, Shiraishi N, Kitano S. Laparoscopic sentinel node navigation achieved by infrared ray electronic endoscopy system in patients with gastric cancer. Surg Endosc. 2007; 21: 1131-4.

114. Nakamura Y, Fujisawa Y, Nakamura Y, Maruyama H, Furuta J, Kawachi Y, et al. Improvement of the sentinel lymph node detection rate of cervical sentinel lymph node biopsy using real-time fluorescence navigation with indocyanine green in head and neck skin cancer. J Dermatol. 2013; 40: 453-7.

115. Schaafsma BE, van der Vorst JR, Gaarenstroom KN, Peters AA, Verbeek FP, de Kroon $\mathrm{CD}$, et al. Randomized comparison of near-infrared fluorescence lymphatic tracers for sentinel lymph node mapping of cervical cancer. Gynecol Oncol. 2012; 127: 126-30.

116. Furukawa N, Oi H, Yoshida S, Shigetomi H, Kanayama S, Kobayashi H. The usefulness of photodynamic eye for sentinel lymph node identification in patients with cervical cancer. Tumori. 2010; 96: 936-40.

117. Rossi EC, Ivanova A, Boggess JF. Robotically assisted fluorescence-guided lymph node mapping with ICG for gynecologic malignancies: a feasibility study. Gynecol Oncol. 2012; 124: 78-82.

118. Schaafsma BE, Verbeek FP, van der Vorst JR, Hutteman M, Kuppen PJ, Frangioni JV, et al. Ex vivo sentinel node mapping in colon cancer combining blue dye staining and fluorescence imaging. J Surg Res. 2013; 183: 253-7.

119. van der Pas MHGM, Ankersmit M, Stockmann HBAC, Silvis R, van Grieken NCT, Bril H, et al. Laparoscopic Sentinel Lymph Node Identification in Patients with Colon Carcinoma Using a Near-Infrared Dye: Description of a New Technique and Feasibility Study. J Laparoendosc Adv Surg Tech A. 2013; 23: 367-71.

120. Hirche C, Mohr Z, Kneif S, Doniga S, Murawa D, Strik M, et al. Ultrastaging of colon cancer by sentinel node biopsy using fluorescence navigation with indocyanine green. Int J Colorectal Dis. 2012; 27: 319-24.

121. Ankersmit $\mathrm{M}$, van der Pas $\mathrm{MH}$, van Dam DA, Meijerink WJ. Near infrared fluorescence lymphatic laparoscopy of the colon and mesocolon. Colorectal Dis. 2011; 13 Suppl 7: 70-3.
122. Rossi EC, Ivanova A, Boggess JF. Robotically assisted fluorescence-guided lymph node mapping with ICG for gynecologic malignancies: A feasibility study. Gynecologic Oncology. 2012; 124: 78-82.

123. Holloway RW, Bravo RAM, Rakowski JA, James JA, Jeppson CN, Ingersoll SB, et al. Detection of sentinel lymph nodes in patients with endometrial cancer undergoing robotic-assisted staging: A comparison of colorimetric and fluorescence imaging. Gynecol Oncol. 2012; 126: 25-9.

124. Levinson KL, Mahdi H, Escobar PF. Feasibility and Optimal Dosage of Indocyanine Green Fluorescence for Sentinel Lymph Node Detection Using Robotic Single-Site Instrumentation: Preclinical Study. J Minim Invas Gyn. 2013; 20: 691-6

125. Schaafsma BE, Verbeek FPR, Peters AAW, van der Vorst JR, de Kroon CD, van Poelgeest MIE, et al. Near-infrared fluorescence sentinel lymph node biopsy in vulvar cancer: a randomised comparison of lymphatic tracers. BJOG. 2013; 120: 758-64.

126. Verbeek FPR, Troyan SL, Mieog JSD, Liefers GJ, Moffitt LA, Rosenberg M, et al. Near-infrared fluorescence sentinel lymph node mapping in breast cancer: multicenter experience. Breast Cancer Res Treat. 2014; 143: 333-42.

127. Morton DL, Bostick PJ. Will the true sentinel node please stand? Ann Surg Oncol. 1999; 6: 12-4.

128. Buckle T, van Leeuwen AC, Chin PT, Janssen H, Muller SH, Jonkers I, et al. A self-assembled multimodal complex for combined pre-and intraoperative imaging of the sentinel lymph node. Nanotechnology. 2010; 21: 355101.

129. Liu Y, Zhao YM, Akers W, Tang ZY, Fan J, Sun HC, et al. First in-human intraoperative imaging of $\mathrm{HCC}$ using the fluorescence goggle system and transarterial delivery of near-infrared fluorescent imaging agent: a pilot study. Transl Res. 2013; 162: 324-31.

130. Satou S, Ishizawa T, Masuda K, Kaneko J, Aoki T, Sakamoto Y, et al. Indocyanine green fluorescent imaging for detecting extrahepatic metastasis of hepatocellular carcinoma. J Gastroenterol. 2013; 48: 1136-43.

131. Morita Y, Sakaguchi T, Unno N, Shibasaki Y, Suzuki A, Fukumoto K, et al. Detection of hepatocellular carcinomas with near-infrared fluorescence imaging using indocyanine green: its usefulness and limitation. Int J Clin Oncol. 2013; 18: 232-41.

132. Uchiyama K, Ueno M, Ozawa S, Kiriyama S, Shigekawa Y, Hirono S, et al. Combined intraoperative use of contrast-enhanced ultrasonography imaging using a sonazoid and fluorescence navigation system with indocyanine green during anatomical hepatectomy. Langenbeck Arch Surg. 2011; 396: 1101-7.

133. Ishizawa T, Fukushima N, Shibahara J, Masuda K, Tamura S, Aoki T, et al. Real-Time Identification of Liver Cancers by Using Indocyanine Green Fluorescent Imaging. Cancer. 2009; 115: 2491-504.

134. Kawaguchi Y, Aoki T, Ishizawa T, Arita J, Satou S, Kaneko J, et al. Education and imaging: Hepatobiliary and pancreatic: Identification of recurrent hepatocellular carcinoma by intraoperative fluorescent imaging. J Gastroenterol Hepatol. 2013; 28: 587.

135. Ishizawa T, Masuda K, Urano Y, Kawaguchi Y, Satou S, Kaneko J, et al. Mechanistic background and clinical applications of indocyanine green fluorescence imaging of hepatocellular carcinoma. Ann Surg Oncol. 2014; 21: 440-8

136. Sturm MB, Joshi BP, Lu SY, Piraka C, Khondee S, Elmunzer BJ, et al. Targeted Imaging of Esophageal Neoplasia with a Fluorescently Labeled Peptide: First-in-Human Results. Sci Transl Med. 2013: 5: 184ra61.

137. Yang LL, Sajja HK, Cao ZH, Qian WP, Bender L, Marcus AI, et al. uPAR-targeted Optical Imaging Contrasts as Theranostic Agents for Tumor Margin Detection. Theranostics. 2014; 4: 106-18

138. Scheuer W, van Dam GM, Dobosz M, Schwaiger M, Ntziachristos V. Drug-based optical agents: infiltrating clinics at lower risk. Sci Transl Med. 2012; 4: 134ps11.

139. [Internet] van Dam GM. VEGF-targeted Fluorescent Tracer Imaging in Breast Cancer. http://clinicaltrials.gov/show/NCT01508572

140. Thorek DLJ, Riedl CC, Grimm J. Clinical Cerenkov Luminescence Imaging of F-18-FDG. J Nucl Med. 2014; 55: 95-8.

141. Laverman P, Sosabowski JK, Boerman OC, Oyen WJ. Radiolabelled peptides for oncological diagnosis. Eur J Nucl Med Mol Imaging. 2012; 39 Suppl 1: S78-92.

142. Carey JN, Rommer E, Sheckter C, Minneti M, Talving P, Wong AK, et al. Simulation of plastic surgery and microvascular procedures using perfused fresh human cadavers. J Plast Reconstr Aesthet Surg. 2014; 67: e42-8.

143. Mieog JSD, Hutteman M, van der Vorst JR, Kuppen PJ, Que I, Dijkstra J, et al. Image-guided tumor resection using real-time near-infrared fluorescence in a syngeneic rat model of primary breast cancer. Breast cancer Res Treat. 2011; 128: 679-89.

144. Sugie T, Kassim KA, Takeuchi M, Hashimoto T, Yamagami K, Masai Y, et al. A novel method for sentinel lymph node biopsy by indocyanine green fluorescence technique in breast cancer. Cancers. 2010; 2: 713-20.

145. Kaushal S, McElroy MK, Luiken GA, Talamini MA, Moossa AR, Hoffman RM, et al. Fluorophore-conjugated anti-CEA antibody for the intraoperative imaging of pancreatic and colorectal cancer. J Gastrointest Surg. 2008; 12: 1938-50.

146. Tran Cao HS, Kaushal S, Metildi CA, Menen RS, Lee C, Snyder CS, et al. Tumor-specific fluorescence antibody imaging enables accurate staging laparoscopy in an orthotopic model of pancreatic cancer. Hepatogastroenterology. 2012; 59: 1994-9.

147. Hutteman M, Mieog JS, van der Vorst JR, Dijkstra J, Kuppen PJ, van der Laan $\mathrm{AM}$, et al. Intraoperative near-infrared fluorescence imaging of colorectal 
metastases targeting integrin alpha(v)beta(3) expression in a syngeneic rat model. Eur J Surg Oncol. 2011; 37: 252-7.

148. Oliveira S, van Dongen GA, Stigter-van Walsum M, Roovers RC, Stam JC, Mali W, et al. Rapid visualization of human tumor xenografts through optical imaging with a near-infrared fluorescent anti-epidermal growth factor receptor nanobody. Mol Imaging. 2012; 11: 33-46.

149. Wu AP, Whitney MA, Crisp JL, Friedman B, Tsien RY, Nguyen QT. Improved facial nerve identification with novel fluorescently labeled probe. Laryngoscope. 2011; 121: 805-10.

150. Olson ES, Whitney MA, Friedman B, Aguilera TA, Crisp JL, Baik FM, et al. In vivo fluorescence imaging of atherosclerotic plaques with activatable cell-penetrating peptides targeting thrombin activity. Integr Biol (Camb). 2012; 4: 595-605.

151. Olson ES, Jiang T, Aguilera TA, Nguyen OT, Ellies LG, Scadeng M, et al. Activatable cell penetrating peptides linked to nanoparticles as dual probes for in vivo fluorescence and MR imaging of proteases. Proc Natl Acad Sci U S A. 2010; 107: 4311-6.

152. Deu E, Verdoes M, Bogyo M. New approaches for dissecting protease functions to improve probe development and drug discovery. Nat Struct Mol Biol. 2012; 19: 9-16..

153. Blum G, Weimer RM, Edgington LE, Adams W, Bogyo M. Comparative assessment of substrates and activity based probes as tools for non-invasive optical imaging of cysteine protease activity. PloS One. 2009; 4: e6374.

154. Blum G, von Degenfeld G, Merchant MJ, Blau HM, Bogyo M. Noninvasive optical imaging of cysteine protease activity using fluorescently quenched activity-based probes. Nat Chem Biol. 2007; 3: 668-77.

155. Gleysteen JP, Duncan RD, Magnuson JS, Skipper JB, Zinn K, Rosenthal EL. Fluorescently labeled cetuximab to evaluate head and neck cancer response to treatment. Cancer Ther. 2007; 6: 1181-5.

156. Lee SB, Hassan M, Fisher R, Chertov O, Chernomordik V, Kramer-Marek G, et al. Affibody molecules for in vivo characterization of HER2-positive tumors by near-infrared imaging. Clin Cancer Res. 2008; 14: 3840-9.

157. Withrow KP, Newman JR, Skipper JB, Gleysteen JP, Magnuson JS, Zinn K, et al. Assessment of bevacizumab conjugated to Cy5. 5 for detection of head and neck cancer xenografts. Technol Cancer Res Treat. 2008; 7: 61-6.

158. Heath CH, Deep NL, Sweeny L, Zinn KR, Rosenthal EL. Use of Panitumumab-IRDye800 to Image Microscopic Head and Neck Cancer in an Orthotopic Surgical Model. Ann Surg Oncol. 2012; 19: 3879-87.

159. Sano K, Mitsunaga M, Nakajima T, Choyke PL, Kobayashi H. In vivo breast cancer characterization imaging using two monoclonal antibodies activatably labeled with near infrared fluorophores. Breast Cancer Res. 2012; 14: R61.

160. van Scheltinga AGTT, van Dam GM, Nagengast WB, Ntziachristos V, Hollema $\mathrm{H}$, Herek JL, et al. Intraoperative Near-Infrared Fluorescence Tumor Imaging with Vascular Endothelial Growth Factor and Human Epidermal Growth Factor Receptor 2 Targeting Antibodies. J Nucl Med. 2011; 52: 1778-85.

161. Ye Y, Chen X. Integrin targeting for tumor optical imaging. Theranostics. 2011; 1: $102-26$

162. Chen $\mathrm{K}$, Xie J, Chen X. RGD-human serum albumin conjugates as efficient tumor targeting probes. Mol Imaging. 2009; 8: 65-73.

163. Smith BR, Cheng Z, De A, Koh AL, Sinclair R, Gambhir SS. Real-time intravital imaging of RGD-quantum dot binding to luminal endothelium in mouse tumor neovasculature. Nano Lett. 2008; 8: 2599-606.

164. Li Y, Li Z, Wang X, Liu F, Cheng Y, Zhang B, et al. In vivo cancer targeting and imaging-guided surgery with near infrared-emitting quantum dot bioconjugates. Theranostics. 2012; 2: 769-76.

165. Weissleder R, Tung $\mathrm{CH}$, Mahmood U, Bogdanov A. In vivo imaging of tumors with protease-activated near-infrared fluorescent probes. Nat Biotechnol. 1999; 17: 375-8.

166. Zhu L, Xie J, Swierczewska M, Zhang F, Quan OM, Ma Y, et al. Real-Time Video Imaging of Protease Expression In Vivo. Theranostics. 2011; 1: 18-27.

167. Wunderbaldinger P, Turetschek K, Bremer C. Near-infrared fluorescence imaging of lymph nodes using a new enzyme sensing activatable macromolecular optical probe. Eur Radiol. 2003; 13: 2206-11.

168. Myochin T, Hanaoka K, Komatsu T, Terai T, Nagano T. Design strategy for a near-infrared fluorescence probe for matrix metalloproteinase utilizing highly cell permeable boron dipyrromethene. J Am Chem Soc. 2012; 134: 13730-7.

169. Barber PA, Rushforth D, Agrawal S, Tuor UI. Infrared optical imaging of matrix metalloproteinases (MMPs) up regulation following ischemia reperfusion is ameliorated by hypothermia. BMC Neurosci. 2012; 13: 76.

170. Lee CM, Jang D, Cheong SJ, Jeong MH, Kim EM, Kim DW, et al. Optical imaging of MMP expression and cancer progression in an inflammation-induced colon cancer model. Int J Cancer. 2012; 131: 1846-53.

171. Ryu JH, Lee A, Huh MS, Chu J, Kim K, Kim BS, et al. Measurement of MMP Activity in Synovial Fluid in Cases of Osteoarthritis and Acute Inflammatory Conditions of the Knee Joints Using a Fluorogenic Peptide Probe-Immobilized Diagnostic Kit. Theranostics. 2012; 2: 198-206.

172. Azhdarinia A, Wilganowski N, Robinson H, Ghosh P, Kwon S, Lazard ZW, et al. Characterization of chemical, radiochemical and optical properties of a dual-labeled MMP-9 targeting peptide. Bioorgan Med Chem. 2011; 19: 3769-76.

173. Ryu JH, Lee A, Lee S, Ahn CH, Park JW, Leary JF, et al. "One-step" detection of matrix metalloproteinase activity using a fluorogenic peptide probe-immobilized diagnostic kit. Bioconjug Chem. 2010; 21: 1378-84.
174. Keereweer S, Kerrebijn JD, van Driel PB, Xie B, Kaijzel EL, Snoeks TJ, et al. Optical image-guided surgery--where do we stand? Mol Imaging Biol. 2011; 13: 199-207.

175. Thorek DLJ, Ogirala A, Beattie BJ, Grimm J. Quantitative imaging of disease signatures through radioactive decay signal conversion. Nat Med. 2013; 19: 1345-50.

176. Chin PTK, Welling MM, Meskers SCJ, Olmos RAV, Tanke $\mathrm{H}$, van Leeuwen FWB. Optical imaging as an expansion of nuclear medicine: Cerenkov-based luminescence vs fluorescence-based luminescence. Eur J Nucl Med Mol Imaging. 2013; 40: 1283-91.

177. Liu HG, Carpenter CM, Jiang H, Pratx G, Sun C, Buchin MP, et al. Intraoperative Imaging of Tumors Using Cerenkov Luminescence Endoscopy: A Feasibility Experimental Study. J Nucl Med. 2012; 53: 1579-84.

178. Luo T, Huang P, Gao G, Shen G, Fu S, Cui D, et al. Mesoporous silica-coated gold nanorods with embedded indocyanine green for dual mode $\mathrm{X}$-ray CT and NIR fluorescence imaging. Opt Express. 2011; 19: 17030-9.

179. Yuasa $Y$, Seike I, Yoshida $T$, Takechi $H$, Yamai $H$, Yamamoto $Y$, et al. Sentinel Lymph Node Biopsy Using Intraoperative Indocyanine Green Fluorescence Imaging Navigated with Preoperative CT Lymphography for Superficial Esophageal Cancer. Ann Surg Oncol. 2012; 19: 486-93.

180. Chen YJ, Wu SC, Chen CY, Tzou SC, Cheng TL, Huang YF, et al. Peptide-based MRI contrast agent and near-infrared fluorescent probe for intratumoral legumain detection. Biomaterials. 2014; 35: 304-15.

181. Zhang F, Zhu L, Huang X, Niu G, Chen X. Differentiation of reactive and tumor metastatic lymph nodes with diffusion-weighted and SPIO-enhanced MRI. Mol Imaging Biol. 2013; 15: 40-7.

182. Huang X, Zhang F, Lee S, Swierczewska M, Kiesewetter DO, Lang L, et al. Long-term multimodal imaging of tumor draining sentinel lymph nodes using mesoporous silica-based nanoprobes. Biomaterials. 2012; 33: 4370-8. 